\title{
What works with men? A systematic review of health promoting interventions targeting men
}

\author{
Lynn M Robertson*1, Flora Douglas ${ }^{1}$, Anne Ludbrook ${ }^{2}$, Garth Reid ${ }^{1}$ and \\ Edwin van Teijlingen ${ }^{1}$
}

\begin{abstract}
Address: ${ }^{1}$ University of Aberdeen, Department of Public Health, Polwarth Building, Foresterhill, Aberdeen, AB25 2ZD, UK and ${ }^{2}$ University of Aberdeen, Health Economics Research Unit, Polwarth Building, Foresterhill, Aberdeen, AB25 2ZD, UK

Email: Lynn M Robertson* - l.robertson@abdn.ac.uk; Flora Douglas - f.douglas@abdn.ac.uk; Anne Ludbrook - a.ludbrook@abdn.ac.uk; Garth Reid - g.reid@abdn.ac.uk; Edwin van Teijlingen - van.teijlingen@abdn.ac.uk

* Corresponding author
\end{abstract}

Published: 3 July 2008

BMC Health Services Research 2008, 8:141 doi:10.1 186/1472-6963-8-14|
Received: II February 2008

Accepted: 3 July 2008

This article is available from: http://www.biomedcentral.com/l472-6963/8//4I

(c) 2008 Robertson et al; licensee BioMed Central Ltd.

This is an Open Access article distributed under the terms of the Creative Commons Attribution License (http://creativecommons.org/licenses/by/2.0), which permits unrestricted use, distribution, and reproduction in any medium, provided the original work is properly cited.

\begin{abstract}
Background: Encouraging men to make more effective use of (preventive) health services is considered one way of improving their health. The aim of this study was to appraise the available evidence of effective interventions aimed at improving men's health.

Methods: Systematic review of relevant studies identified through 14 electronic databases and other information resources. Results were pooled within health topic and described qualitatively.

Results: Of 1I,749 citations screened, 338 articles were assessed and 27 met our inclusion criteria. Most studies were male sex-specific, i.e. prostate cancer screening and testicular selfexamination. Other topics included alcohol, cardiovascular disease, diet and physical activity, skin cancer and smoking cessation. Twenty-three interventions were effective or partially effective and 18 studies satisfied all quality criteria.

Conclusion: Most of the existing evidence relates to male sex-specific health problems as opposed to general health concerns relevant to both men and women. There is little published evidence on how to improve men's uptake of services. We cannot conclude from this review that targeting men works better than providing services for all people. Large-scale studies are required to help produce evidence that is sufficiently robust to add to the small evidence base that currently exists in this field.
\end{abstract}

\section{Background}

Over the past decade, men's health has increasingly become a public health concern. Whilst their health has been improving over time, men still have a lower life expectancy than women. With the exception of Alzheimer's disease, men had higher mortality rates than women for the 15 leading causes of death in the US in 1999 [1]. Moreover, there are marked health inequalities between men living under different social circumstances [2].

Encouraging men to make more effective use of health services is considered one means of improving men's health, since there are significant differences in the way men and women seek help about health concerns [3]. Men tend to visit their doctor later in the course of a con- 
dition than women and this has been associated with poorer health outcomes [4,5]. Banks [5] also argues that better use would be made of existing health services if these were more "male friendly" in terms of convenience and anonymity.

It has been suggested that men have a very functional view of their bodies and see health care as a 'fix-it' cure; therefore they may respond better to health care interventions that offer tests, facts and figures, e.g. cholesterol, blood pressure [6,7]. The importance of female partners' support and influence on men's health behaviours has also been highlighted $[8,9]$. Thus, a potentially effective way to change men's behaviour, particularly their use of primary care, may be to target women who act as motivators of help-seeking behaviours among men [1]. Some authors have also advocated more proactive approaches in efforts to encourage men to use health care services earlier, such as outreach services $[4,10]$.

There have been several well men's health initiatives introduced in the UK [11], but their effectiveness is not known. Previous reviews have focused on interventions aimed at reducing sexual risk behaviour among men [1218]. Other than the area of sexual health, we know of no systematic reviews of specifically designed interventions aimed at men. This systematic review aimed to appraise the available evidence of effective interventions aimed at improving men's health.

\section{Methods}

\section{Identifying relevant studies}

Systematic searches were conducted in a wide range of electronic databases and other information resources to locate both published and unpublished studies in the English language from 1990 to April 2006. Only English language studies were included because of lack of resources. Studies were sought by systematic searching of three key journals: Journal of Men's Health and Gender, Men's Health Journal and The International Journal of Men's Health; 14 electronic databases; men's health websites; scanning reference lists of already identified relevant studies; and through personal contacts. A search strategy was devised for use with MEDLINE and adapted for other databases (see Additional file 1). Two independent reviewers assessed articles for inclusion and extracted data using standardized data abstraction forms. Any discrepancies were resolved by consulting a third reviewer.

\section{Criteria for considering studies for this review}

Primary studies evaluating the effectiveness of interventions targeting men were included. These interventions could be directed either at improving specific health outcomes or improving men's uptake of services.
Studies were selected according to the following criteria: (a) participants: healthy, free-living adult men $\geq 18$ years; (b) intervention: aimed at improving men's health; (c) setting: conducted in industrialised/developed countries; (d) outcomes: health status, knowledge, attitudes, behaviour, behaviour intentions; and (e) study design: randomised controlled trials (RCTs), quasi-randomised controlled trials (quasi-RCTs, non random allocation), controlled before-and-after studies. Studies were excluded if they concerned sexual health only, as several reviews already existed in this area.

\section{Quality Assessment}

Studies were classified according to four criteria: (1) employing an appropriate control group; (2) providing pre-intervention data for all individuals; (3) providing post-intervention data for all individuals; and (4) reporting findings for each outcome measure indicated in the aims of the study [17]. When commenting on the studies, account has also been taken of the size of the study samples and the generalisability of the populations studied.

\section{Results}

Literature identification, study characteristics and quality Of 11,749 citations screened, 338 articles were assessed and 27 met our inclusion criteria (see Table 1). Eighteen studies were RCTs, three quasi-RCTs and the remaining six were controlled before-and-after designs. Seventeen studies $(63 \%)$ were male sex-specific, i.e. prostate cancer screening and testicular self-examination. Other health topics included alcohol, cardiovascular disease, diet and physical activity, skin cancer and smoking cessation. There were no specific studies on drug use or mental health. In three studies, the interventions were designed to improve attendance rates. The majority were in primary care $(67 \%)$ and US-based (59\%). In just over half of the studies, a theoretical framework guided the development and/or delivery of the intervention. Twenty-three interventions were effective or partially effective and 18 studies satisfied all quality criteria.

\section{Smoking cessation}

Three studies of effective smoking cessation interventions were found. Two were RCTs; one using self-help manuals [19] and one using video and nicotine replacement therapy plus other support materials [20]. The third study was a controlled before-and-after comparison of a media-led anti-tobacco campaign [21]. All studies showed a higher quit rate in the intervention group but relied heavily on self-reported smoking status. Pallonen et al. [19] reported seven-day abstinence rates of $10 \%$ (intervention) and $6 \%$ (control) after two years. Stanton et al. [20] reported quit rates at the end of the partner's pregnancy of $16.5 \%$ (intervention) and 9.3\% (control) and validated their results with carbon monoxide readings for a sub-sample. Jenkins 
Table I: Characteristics of Included Studies

\begin{tabular}{|c|c|c|}
\hline Author Setting Participants & Study Design Outcomes & Intervention Control/Comparison \\
\hline \multicolumn{3}{|c|}{ Smoking Cessation } \\
\hline $\begin{array}{l}\text { Jenkins et al. } 1997 \\
\text { Community, USA } \\
n=|4| \mid \\
\text { I8+ years } \\
\text { Vietnamese speaking }\end{array}$ & $\begin{array}{l}\text { Controlled before-and-after } \\
\text { I. Proportion of current smokers } \\
\text { 2. Proportion who had quit smoking }\end{array}$ & $\begin{array}{l}\text { Intervention: Media-led anti-tobacco campaign San } \\
\text { Francisco. Over } 2 \text { years } \\
\text { Control: Comparison community. }\end{array}$ \\
\hline $\begin{array}{l}\text { Pallonen, } \mathbf{U} \text {. E. et al. } 1994 \\
\text { Primary care, Finland } \\
n=375 \\
42-60 \text { years }\end{array}$ & $\begin{array}{l}\text { RCT } \\
\text { I. } 7 \text { day point prevalence abstinence. } \\
\text { 2. Prolonged abstinence } \\
\text { 3. Probability of stage changes } \\
\text { 4. Exposure and subject evaluation of intervention }\end{array}$ & $\begin{array}{l}\text { Intervention: Self help manuals } 2 \text { years } \\
\text { Control: Usual care }\end{array}$ \\
\hline $\begin{array}{l}\text { Stanton et al. } 2004 \\
\text { Primary care, Australia } \\
n=56 \mid \\
16-56 \text { years } \\
\text { Partners are pregnant }\end{array}$ & $\begin{array}{l}\mathrm{RCT} \\
\text { Quit rate at end of pregnancy }\end{array}$ & $\begin{array}{l}\text { Video/NRT and information/support material. } \\
\text { Control: Brochure providing contact details for the } \\
\text { available smoking cessation options. }\end{array}$ \\
\hline
\end{tabular}

\section{Cook et al. 200I}

Workplace, New Zealand

$\mathrm{n}=253$

mean 35 years at intervention site

mean $\mathbf{4 2 . 9}$ years at control site

male employees

Williams and Lewis 2002

University, USA

$\mathrm{n}=45$

20-25 years, mean 21.5

\section{Diet and Physical Activity}

Controlled before-and-after

I. Dietary and lifestyle behaviours

2. Nutrition knowledge

3. BMI

4. Waist circumference

5. BP

RCT

I. Percent calories from fat

2. Assessment of counselling
Intervention: Health promotion programme - 30 min workshop once a month for 6 months Control: No treatment

I. Nutrition counselling and measurement of cholesterol (NC + SC)

2. Nutrition counselling only (NC)

3. Measurement of serum cholesterol only (SC)

Control: No intervention.
McCrone et al. 200 I

Primary care, USA

$\mathrm{n}=33$

57-78 years

Pritchard et al. 2002

Workplace, Australia

$\mathrm{n}=66$

mean 43.4 years

overweight men

\section{Cardiovascular Disease}

Controlled before-and-after

I. Body composition

2. Metabolism

3. CV fitness
Intervention: SM: Multibehavioural stress management (nutrition, exercise and stress management)

Control: ED: Multibehavioural educational intervention (nutrition, exercise and education) 6 months

Exercise physiologist, dietitian and nurse.

I. Dietary intervention - low-fat diet using the National Heart Foundation booklet, The Weight Loss Guide

2. Exercise intervention - subjects selected own exercise for a min $3 \times 30$ mins p/week above their pre-study exercise level

(12 months)

Control: Maintain pre-study dietary and activity patterns ( 16 of control group followed a diet and exercise program for a subsequent 12 months).
Davison et al. 1999

Primary care, Canada

$\mathrm{n}=100$

$50-79$ years, mean 62.1

Flood et al. 1996

Primary care, USA

Study I: $\mathrm{n}=409$

Study $2: \mathrm{n}=222$

$50+$ years

\section{Prostate Cancer}

RCT

I. Preferred and assumed roles in screening decision making

2. Levels of state anxiety

3. Levels of decisional conflict

4. Screening behaviour

Quasi RCT

I. Knowledge concerning prostate cancer and screening

2. Preference regarding treatment and screening
Intervention: Verbal and written information about the controversies surrounding screening for prostate cancer.

Control: Investigator talked about general issues.

Study I Intervention: Educational video Control: Control video

Study 2 Intervention: Educational video

Control: No intervention 
Table I: Characteristics of Included Studies (Continued)

Frosch et al. 2003
Primary care, USA
$\mathrm{n}=226$
$50+$ years

Gattellari and Ward 2005
Community, Australia
$\mathrm{n}=42$ I
$50-70$ years

Hammond et al. 200I

Primary care, USA

$\mathrm{n}=1959$

mean 66.5 years

Myers et al. 1999

Primary care, USA

$\mathrm{n}=413$

40-70 years

African American

Myers et al. 2005

Primary care, USA

$\mathrm{n}=242$

$\geq 40$ years

African American

Partin et al. 2004
Primary care, USA
$\mathrm{n}=1152$

$\geq 50$ years
RCT

Primary outcomes:

I. Convenience, effort required, satisfaction with

2. Knowledge

3. Choice of PSA test

Also secondary outcomes.

\section{RCT}

I. Knowledge 2. Views towards PSA screening 3. Decisional conflict (post-test only) 4. Decisional control 5. Worry

6. Perceived ability to make informed choice 7. Propensity to undergo PSA screening during next 12 months 8 . Likelihood of accepting doctor's recommendation to go to PSA screening (post test only) 9. Scenario-based assessment 10. Perceptions of GP fault regarding adverse consequences of screening decisions II. Demographic and health info 12. Evaluation of materials received (post test).

$\mathrm{RCT}$, cluster randomisation

I. Health Status 2. Urinary symptoms 3 . Treatment received 4. Prostate related knowledge 5 . Physicians management of prostate conditions

RCT

Adherence (to come for education and early detection)

RCT

Digital rectal examination (DRE)

Prostate specific antigen (PSE)

\section{RCT}

I. Screening knowledge

2. Decision-making participation

3. Preferences

4. Behaviours

Controlled before-and-after, staged

I. Knowledge

2. Preference for PSA test

3. Satisfaction with care

4. Assessment of Video

5I-77 years, mean 66

Schapira and Van Ruiswyk 2000 Primary care, USA

$\mathrm{n}=257$

50-80 years

Summer et al. 2002

Workplace, England

$\mathrm{n}=458$

Volk et al. 2003

I. Prostate cancer screening knowledge

2. Prostate cancer screening beliefs

3. Prostate cancer screening decisions (post-test)

Controlled before-and-after

I. Knowledge

2. Intentions to seek help

3. Attitudes to health promotion in the workplace

4. Process indicators

RCT

Follow-up of Volk et al. 1999 at I year I. Screening behaviours

Primary care, USA

2. Satisfaction with screening decision

$\mathrm{n}=160$

$45-70$ years

Volk et al. 1999

Primary care, USA

$\mathrm{n}=160$

45-70 years

Weinrich et al. 1998

Primary care, USA

$\mathrm{n}=1717$

$40-70$ years, mean 52

\section{RCT}

I. Knowledge of prostate cancer

2. Reported preferences for PSA testing

3. Ratings of the videotape

Quasi, 2 by 2 factorial, randomly assigned

Participation in free prostate cancer screening intervention.

Intervention: Prostate cancer education

website

Control: Prostate cancer education video

Comparing 3 educational resources

I. Leaflet

2. Video

3. Booklet

Intervention: Practice intervention for physicians. Patient brochures, 2 videotapes. 18 months

Control: Usual care

Intervention: Print materials and telephone contacts. "Pro-record" tailored to each recipient educational booklet.

Control: Print material and telephone contacts.

Intervention: Enhanced Intervention (EI)

Information book and screening decision

educational session.

Control: Standard Intervention (SI) Information

Booklet

I. Mailed pamphlet

2. Mailed video

No intervention

Intervention: Educational video "The PSA Decision: What you Need to Know". 20 minutes.

Control: Usual care.

Intervention: Illustrated pamphlet (decision-aid). Control: Written pamphlet.

Site I: Posters and leaflets

Site 2: Posters and leaflets, visit by nurse

Site 3: Posters and leaflets, visit by nurse and team of 8 men's health volunteers

20 minute educational video on advantages and disadvantages of PSA screening and accompanying brochure.

Control: No intervention
20 minute educational video on advantages and disadvantages of PSA screening and accompanying brochure.

Control: No intervention.

I. Traditional

2. Peer-educator

3. Client-navigator

4. Combination of peer-educator and clientnavigator 
Table I: Characteristics of Included Studies (Continued)

\begin{tabular}{lll}
\hline Wilt et al. 200I & RCT & Intervention: "Early Prostate Cancer" pamphlet \\
Primary care, USA & I. Knowledge about early detection and treatment & mailed I week before clinic appointment. \\
$\mathrm{n}=550$ & 2. PSA testing & Control: Usual care. \\
$50+$ years & &
\end{tabular}

\begin{tabular}{lll} 
McCullagh et al. 2005 & \multicolumn{2}{c}{ Testicular Cancer } \\
Workplace and leisure sites, UK & Controlled before-and-after & Intervention: Check'Em Out information resources \\
$\mathrm{n}=835$ & I. Knowledge & at workplace and leisure sites. \\
I5-44 years & 2. Intention to perform TSE & Control: No intervention \\
Steadman and Quine $\mathbf{2 0 0 4}$ & Practice of TSE & Intervention: Implementation intentions (IIllustrated \\
University, England & RCT & leaflet containing detailed instructions on how to \\
$n=159$ & I. Performance of TSE & perform TSE.) \\
I8-35 years & 2. Future intention to perform TSE & Control: Illustrated leaflet only.
\end{tabular}

\section{Holland 2005 \\ Primary Care, USA \\ $\mathrm{n}=5677$ \\ $40-60$ years}

\section{Preventive Health Screening}

RCT

I. Colorectal cancer screening

2. Cholesterol screening

3. Prostate cancer screening

4. Preventive health care visits
Intervention Matrix: Health provider stickers, letter/pamphlet, loved-one postcard.
Skin Cancer

RCT

Rates of attendance
Intervention: Personalised letter plus information brochure

Control: Personalised letter

Primary Care, Australia

$\mathrm{n}=1322$

30-79 years

\author{
Alcohol \\ Karlsson et al. 2005 \\ Community, Finland \\ $\mathrm{N}=4418$ \\ $30-49$ years
}

Controlled before-and-after.

I. Drinking behaviour (AUDIT)

2. Annual alcohol consumption
Intervention: Self help pamphlet

Control: No intervention

\begin{abstract}
AUDIT = Alcohol Use Disorders Identification Test, $\mathrm{BMI}=$ body mass index, $\mathrm{BP}=$ blood pressure, $\mathrm{CV}=$ cardiovascular, $\mathrm{DRE}=$ digital rectal examination, NRT $=$ nicotine replacement therapy, PSA $=$ prostate-specific antigen, $\mathrm{RCT}=$ randomised controlled trial, TSE $=$ testicular selfexamination.
\end{abstract}

et al. [21] found that smoking prevalence fell by $2.2 \%$ points over two years in the target area and increased by $1.3 \%$ points in the control area.

\section{Diet and physical activity}

Two studies, aimed at improving diet and physical activity were identified $[22,23]$ both showing the interventions to be partially effective. One RCT was small $(n=45)$ and compared a combination of nutrition counselling (NC) and serum cholesterol measurement (SC) interventions with no intervention. The $\mathrm{NC}+\mathrm{SC}$ group showed significant reductions in fat intake over a six-week period (3.2\%) based on self-reported food intake over 24 hour periods [22]. Cook et al. [23] reported on a workplace intervention, consisting of a monthly health promotion workshop. Significant self-reported changes were made in vegetable intake, physical activity and dietary knowledge compared with a control site. Changes in fruit intake, and eating breakfast were not significant. There was a significant reduction in systolic blood pressure (BP) but no difference was found for diastolic BP, body mass index (BMI) or waist circumference.

\section{CVD risk factors}

There was considerable overlap in approach between studies aimed at cardiovascular risk factors and those aimed at diet and physical activity. A small RCT $(n=66)$ at a workplace in Australia found that low fat diet and/or exercise interventions were effective, although no one strategy showed significant benefit over the other [24]. Another small controlled before-and-after study compared stress management $(\mathrm{n}=25)$ and education $(\mathrm{n}=8)$ when combined with nutrition and exercise interventions [25]. This study showed stress management to be more effective on a number of variables.

\section{Prostate cancer}

This was the largest group of studies comprising 11 RCTs [26-36], two quasi RCTs $[37,38]$ and two controlled before-and-after studies $[39,40]$. Most studies concerned the provision of education about screening and treatment options. A range of interventions, including verbal information, written information and videos, were shown to be effective in raising levels of knowledge and increasing the involvement of men in decision making about screen- 
ing. In some studies, particularly in the US, this led to reductions in demand for screening.

\section{Testicular cancer}

Two studies regarding testicular self-examination (TSE) were identified $[41,42]$. In one study, the intervention group was instructed to formulate specific plans for when and where they would perform TSE [41]. In the intervention group, self reported TSE was significantly higher than in the control group (65\% versus $40 \%$ ) but there was no difference between the groups in future intention to perform TSE. In another study [42], information resources were provided at workplace and leisure sites. In the intervention group there was a significant increase in knowledge and performing TSE.

\section{Preventive Health Screening}

One US study [43] evaluated the effectiveness of patient and/or physician interventions (including targeting partners) to increase men's utilization of preventive healthcare services (annual health assessment, colorectal cancer screening, prostate cancer screening and cholesterol screening). Men in the intervention groups were more likely to receive preventive healthcare office visits, cholesterol screenings and prostate cancer screenings. None of the interventions had a significant impact on the number of men who received colorectal cancer screenings.

\section{Skin Cancer}

One RCT addressed the issue of screening for skin cancer among men in Australia [44]. The study assessed the impact of two methods of encouraging men to attend skin screening clinics, a personalised letter or the letter plus an additional brochure. Overall, there was no difference in rates of attendance between the groups. The addition of health information through the use of a glossy brochure increased rates of attendance among younger men (30 to 49 years).

\section{Alcohol}

One Finnish study assessing alcohol consumption was identified [45]. This controlled before-and-after study evaluated the impact of a self-help pamphlet to support self-control of drinking. Overall there were no significant changes in drinking behaviour or consumption. Among "risky male drinkers" there was a significant reduction in Alcohol Use Disorders Identification Test (AUDIT) scores at the second follow-up, but no change in the level of drinking.

\section{Discussion}

The review established that despite the relatively emergent status of men's health, a fair amount of literature exists on the topic as 338 articles were identified during the literature search. However, a large proportion described the set- ting-up and functioning of well-man programmes, and did not include formal evaluations relating to outcomes; as a result only 27 articles were included in the final review.

The majority of studies were concerned with decisionmaking processes and knowledge about prostate cancer screening. This is not surprising due to the considerable debate around the effectiveness of prostate cancer screening. The UK National Screening Committee [46] recommended that prostate cancer screening should not be introduced and that men should not be invited for prostate-specific antigen (PSA) testing in the way that women are invited for mammography.

The literature suggests that interventions may be more likely to be effective if they are theory-based [47]. In just under half of the studies in our review, a theoretical framework guided the development and/or delivery of the intervention. These included the transtheoretical model, transtheoretical cognitive-behavioural social learning model, decision-making theory, preventive health model and implementation intentions. Decision-making theory was most widely used within prostate cancer education interventions.

One study in this review assessed whether the addition of cholesterol measurement would increase the effectiveness of nutrition counselling in male university students [22]. Results indicated that the effectiveness of nutrition counselling was slightly increased when combined with cholesterol measurements, although measurement of cholesterol alone was not shown to be effective.

Only one study targeted men's partners [43]. Results showed that communicating with a man's loved one combined with a reminder system for providers was associated with increase in preventive healthcare screenings. The importance of family and friends in mediating health service usage is also stressed in the literature. This is not simply because the pressure from peers leads them to do it "but rather that they can maintain face or keep their male identity intact, by claiming to be pressurised into it" [48:113]. However, such indirect targeting may be seen as controversial, regardless of this evidence from the literature.

Four studies were workplace-based $[23,24,40,42]$. The workplace is increasingly being used as a setting to gain access to men for the provision of health information and consultation with a health professional [49]. However, this can only benefit men in employment, and not those who are arguably more in need, eg homeless, unemployed. 
Excluding the studies relating to sex-specific interventions, there were only three specifically designed to be suitable for men only $[20,43,44]$ and a fourth intervention was delivered at a manufacturing worksite that was male only [23]. In the study by Stanton and colleagues [20], one component of the intervention was a video introduced by a national football personality focusing on becoming a father and on the passive smoking health risks for the newborn. To communicate directly with the targeted male, Holland and colleagues [43] created personalised letters that focused on the recommended preventive health screenings necessary for men in that age range. The letters also indicated the importance of establishing a relationship with a doctor. Addressing the issue of skin cancer screening, Youl and colleagues [44] developed promotional material that included a letter of invitation signed by a popular Australian sportsman, and a brochure highlighting the tendency of men to delay having a skin examination and the fact that men, more frequently than women, died from melanoma.

Many of the interventions were sex specific, rather than gender sensitive, i.e. they aimed to prevent diseases unique to men, such as prostate cancer. Some interventions were targeted at men, but these were not necessarily designed specifically for men, some were workplace interventions. In other words, they targeted settings or localities where men came together, such as male dominated workplaces or sports clubs. Finally, we identified only three interventions which were specifically designed with men in mind, and that can probably be called 'gender' sensitive. We would like to argue that no single one of these three approaches is necessarily better than the others, as Galdas et al. [50] reminded us "not all men are the same, nor does it make sense to assume that individual men behave similarly in all help-seeking contexts."

\section{Limitations of Study}

The majority of studies in our review reported effective interventions. However, publication bias is a possibility, as studies with significantly positive results are more likely to be published than those with non-significant or negative results [51].

Only RCTs and controlled before and after studies were included in this review. However, we are aware that a number of process evaluations have been carried out in the UK [52-54]. We are also aware that there are published evaluations of generic interventions providing separate results for men and women, which have not been assessed in this review as they did not involve targeting men.

\section{Conclusion}

Most of the existing evidence relates to male sex-specific services eg prostate cancer, as opposed to general services directed at problems experienced by both men and women. Of the non sex-specific interventions, only four were for men only in either content or setting. Therefore, we cannot conclude from this review that targeting men works better than delivering a general service to all people. There is little published evidence on how to improve men's uptake of services and it remains unclear whether it is more effective to provide different services or the same services in a different way.

In order to make recommendations on future gender specific services, it is important for policy-makers to appraise the effectiveness of targeting health promotion interventions at men compared with the same interventions aimed at men and women in general or at various subgroups of the population with particular needs not necessarily related to sex or gender (deprived communities, ethnic background, age etc).

The area of men's health is still a young area of interest and good evaluations are needed to generate evidence (either way). Large-scale studies should be funded to help produce evidence that is sufficiently robust to add to the small evidence base that currently exists in this field.

\section{Competing interests}

The authors declare that they have no competing interests.

\section{Authors' contributions}

LMR developed and performed searches, screened search results, organised retrieval of papers, abstracted data from papers, performed data synthesis and wrote the manuscript. FD, AL and EvT were involved in drafting and revising the manuscript. AL participated in the data analysis. GR assisted in screening search results. All authors contributed to the design of the review, screened selected papers against inclusion criteria, participated in the interpretation of the data and gave final approval of the version to be published.

\section{Additional material}

\section{Additional file 1}

Search sources and strategies.

Click here for file

[http://www.biomedcentral.com/content/supplementary/14726963-8-141-S1.doc]

\section{Acknowledgements}

This study was funded as part of a larger evaluation of well men health service pilots by the Scottish Executive Social Research, St Andrews House, Edinburgh, EHI 3DG. Core funding to HERU from the Chief Scientist Office, Scottish Government Health Directorate, is also gratefully acknowl- 
edged. All views expressed are those of the authors and should not be attributed to any funding body.

\section{References}

I. Sadovsky R: Men's healthcare needs improvement: A recommendation for a midlife men's health assessment visit. The Journal of Men's Health \& Gender 2005, 2(3):375-38I.

2. ISD Scotland: Coronary Heart Disease. 2006 [http://www.isd scotland.org/isd/information-and-statis tics.jsp?pConnD=3090\&p applic=CCC\&p service=Content.show\&]

3. Lloyd T, Forrest S: Boys' and Young Men's health. A Literature and Practice Review: An Interim Report. London: Health Development Agency; 200I.

4. Doyal L: Sex, gender, and health: the need for a new approach. BM] 200I, 323(7320): |06|-1063.

5. Banks I: No man's land: men, illness, and the NHS. BMJ 200I, 323(7320): 1058-1060.

6. Cameron E, Bernardes J: Gender and disadvantages in health men's health for a change. Sociol Health IIIn I998, 20(5):673-693.

7. White A: How men respond to illness. Men's Health Journal 200I, I(I): 18-19.

8. Norcross WA, Ramirez C, Palinkas LA: The influence of women on the healthcare seeking behavior of men. J Fam Pract 1996, 43(5):475-480.

9. Sharpe S: Attitudes and beliefs of men and their health. Men's Health Journal 2002, I(4): I I8- I 20.

10. Wilkins D: 'Getting It Sorted': Identifying and implementing practical solutions to men's health. The Journal of Men's Health \& Gender 2005, 2(I): 13-16.

I I. Johnson L, Rafferty M: Men's Health in Scotland: Mapping male health focused work currently being carried out across Scotland. Edinburgh: Scottish Executive; 2004.

12. Elwy AR, Hart G], Hawkes S, Petticrew M: Effectiveness of inter ventions to prevent sexually transmitted infections and human immunodeficiency virus in heterosexual men: A systematic review. Arch Intern Med 2002, I62(16): 1818-1830.

13. Exner TM, Gardos PS, Seal DW, Ehrhardt AA: HIV sexual risk reduction interventions with heterosexual men: the forgotten group. AIDS and Behav 1999, 3(4):347-58.

14. Choi KH, Coates TJ: Prevention of HIV-Infection. AIDS 1994, 8(10): $|37|-\mid 389$.

15. Johnson WD, Hedges LV, Diaz RM: Interventions to modify sexual risk behaviors for preventing HIV infection in men who have sex with men. Cochrane Database Sys Rev 2003, I:CD00 I230.

16. Oakley A, Oliver S, Peersman G, Mauthner M: Review of effectiveness of health promotion interventions for men who have sex with men. London: EPPI-Centre, Social Science Research Unit, Institute of Education, University of London; 1996.

17. Rees R, Kavanagh J, Burchett H, Shepherd J, Brunton G, Harden A Thomas J, Oliver S, Oakley A: HIV Health promotion and Men who have Sex with Men (MSM): A systematic review of research relevant to the development and implementation of effective and appropriate interventions. London: EPPI-Centre, Social Science Research Unit, Institute of Education, University of London; 2004.

18. McKay A: Prevention of sexually transmitted infections in different populations: A review of behaviourally effective and cost-effective interventions. Can J Hum Sex 2000, 9(2):95-120.

19. Pallonen UE, Leskinen L, Prochaska JO, Willey CJ, Kaariainen R, Salonen JT: A 2-year self-help smoking cessation manual intervention among middle-aged Finnish men: an application of the transtheoretical model. Prev Med 1994, 23(4):507-5I4.

20. Stanton WR, Lowe JB, Moffatt J, Del Mar CB: Randomised control trial of a smoking cessation intervention directed at men whose partners are pregnant. Prev Med 2004, 38(I):6-9.

21. Jenkins $\mathrm{CNH}, \mathrm{McPhee}$ S], Pham GQ, Le A, Ha N, Stewart S: The effectiveness of a media-led intervention to reduce smoking among Vietnamese-American men. Am J Public Health 1997 87(6): $|03|-4$

22. Williams DR, Lewis NM: Effectiveness of nutrition counseling in young adult males. Nutr Res 2002, 22(8):91।-917.

23. Cook C, Simmons G, Swinburn B, Stewart J: Changing risk behaviours for non-communicable disease in New Zealand working men-is workplace intervention effective? N Z Med / 200I, I | 4( I | 30): | 75- | 78 .
24. Pritchard JE, Nowson CA, Billington T, Wark JD: Benefits of a yearlong workplace weight loss program on cardiovascular risk factors. Nutrition \& Dietetics: Journal of the Dietitians Association of Australia 2002, 59(2):87-96.

25. McCrone SH, Brendle D, Barton $\mathrm{K}$ : A multibehavioral intervention to decrease cardiovascular disease risk factors in older men. AACN Clin Issues 200I, I 2(I):5-I6.

26. Davison BJ, Kirk P, Degner LF, Hassard TH: Information and patient participation in screening for prostate cancer. Patient Education \& Counseling 1999, 37(3):255-263.

27. Frosch DL, Kaplan RM, Felitti V]: A randomized controlled trial comparing internet and video to facilitate patient education for men considering the prostate specific antigen test. J Gen Intern Med 2003, I 8(1 0):781-787.

28. Gattellari M, Ward JE: A community-based randomised controlled trial of three different educational resources for men about prostate cancer screening. Patient Education \& Counseling 2005, 57(2): 168-182.

29. Hammond CS, Wasson JH, Walker-Corkery E, Fowler FJ, Barry MJ: A frequently used patient and physician-directed educational intervention does nothing to improve primary care of prostate conditions. Urology 200I, 58(6):875-88I

30. Myers RE, Chodak GW, Wolf TA, Burgh DY, McGrory GT, Marcus SM, Diehl JA, Williams M: Adherence by African American men to prostate cancer education and early detection. Cancer 1999, 86(I):88-104.

31. Myers RE, Daskalakis C, Cocroft J, Kunkel EJS, Delmoor E, Liberatore M, Nydick RL, Brown ER, Gay RN, Powell T, Powell RL: Preparing African-American men in community primary care practices to decide whether or not to have prostate cancer screening. I Natl Med Assoc 2005, 97(8): I | 43- I I 54.

32. Partin $M R$, Nelson $D$, Radosevich $D$, Nugent $S$, Flood $A B$, Dillon $N$ Holtzman J, Haas M, Wilt TJ: Randomized Trial Examining the Effect of Two Prostate Cancer Screening Educational Interventions on Patient Knowledge, Preferences, and Behaviors. J Gen Intern Med 2004, 19:835-842.

33. Schapira MM, VanRuiswyk J: The effect of an illustrated pamphlet decision-aid on the use of prostate cancer screening tests. J Fam Pract 2000, 49(5):4 18-424

34. Volk RJ, Cass AR, Spann S]: A randomized controlled trial of shared decision making for prostate cancer screening. Arch Fam Med 1999, 8(4):333-340.

35. Volk RJ, Spann SJ, Cass AR, Hawley ST: Patient education for informed decision making about prostate cancer screening: a randomized controlled trial with I-year follow-up. Ann Fam Med 2003, I ( I):22-28.

36. Wilt T], Paul J, Murdoch M, Nelson D, Nugent S, Rubins HB: Educating men about prostate cancer screening. A randomized trial of a mailed pamphlet. Eff Clin Pract 200I, 4(3): I I 2- I 20.

37. Flood AB, Wennberg JE, Nease RF Jr, Fowler FJ Jr, Ding J, Hynes LM: The importance of patient preference in the decision to screen for prostate cancer. Prostate Patient Outcomes Research Team. I Gen Intern Med 1996, I I (6):342-349.

38. Weinrich SP, Boyd MD, Weinrich M, Green F, Reynolds WAJ, Metlin $C$ : Increasing prostate cancer screening in African American men with peer-educator and client-navigator interventions. J Cancer Educ 1998, I3(4):2 I3-9.

39. Ruthman JL, Ferrans CE: Efficacy of a video for teaching patients about prostate cancer screening and treatment. Am J Health Promot 2004, I 8(4):292-295

40. Summer S, Dolan A, Thompson V, Hundt GL: Prostate health awareness - promoting men's health in the workplace. Men's Health Journal 2002, I(5): | $46-148$.

4I. Steadman L, Quine L: Encouraging young males to perform testicular self-examination: a simple, but effective, implementation intentions intervention. $\mathrm{Br} J$ Health Psychol 2004 4:479-487.

42. McCullagh J, Lewis G, Warlow C: Promoting awareness and practice of testicular self-examination. Nurs Stand 2005 I9(5I):4I-49.

43. Holland DJ: Sending men the message about preventive care: an evaluation of communication strategies. International Journal of Men's Health 2005, 4(2):97-II4.

44. Youl PH, Janda M, Lowe JB, Aitken JF: Does the type of promotional material influence men's attendance at skin screening clinics? Health Promot J Austr 2005, I 6(3):229-232. 
45. Karlsson T, Raitasalo K, Holmila M, Koski-Jannes A, Ollikainen H, Simpura J: The impact of a self-help pamphlet on reducing risk drinking among 30- to 49-year-old men in Helsinki, Finland. Subst Use Misuse 2005, 40(I 2): | 83 I- I 847.

46. National Screening Committee: Population Screening for Prostate Cancer. 2006 [http://www.library.nhs.uk/screening/ViewRe source.aspx?res|D=6| | 53\&tab|D=288\&cat|D=|347]. UK: National Screening Committee

47. Jackson CNH, Waters E, for the Guidelines for Systematic Reviews of Health Promotion and Public Health Interventions Taskforce: Guidelines for Systematic reviews of health promotion and public health interventions. Version 1.2. Australia: Deakin University; 2005.

48. Robertson A: Men managing health. Men's Health Journal 2003, 2(4): I I - I I3.

49. Davidson N, LLoyd T, Banks I, Royal College of Nursing: Promoting men's health: a guide for practitioners London: Bailliere Tindall; 200I.

50. Galdas PM, Cheater F, Marshall P: Men and health help-seeking behaviour: literature review. Journal of Advanced Nursing 2005, 49(6):616-623.

51. Egger M, Dickersin K, Smith GD: Problems and limitations in conducting systematic reviews. In Systematic Reviews in Healthcare 2nd edition. Edited by: Egger M, Smith GD, Altman DG. London: BMJ Publishing Group; 200I.

52. Leishman J, Dalziel A: Taking action to improve the health of Scottish men. Men's Health Journal 2003, 2(3):90-93.

53. Turnbull G: Preston Men's Health Project Evaluation Report. Lancaster: St Martin's College; 2004.

54. White A, Cash K: Report on the first phase of the study on men's usage of the Bradford Health of Men services. Leeds: Leeds Metropolitan University; 2005.

\section{Pre-publication history}

The pre-publication history for this paper can be accessed here:

http://www.biomedcentral.com/1472-6963/8/141/pre

pub

Publish with Bio Med Central and every scientist can read your work free of charge

"BioMed Central will be the most significant development for disseminating the results of biomedical research in our lifetime. "

Sir Paul Nurse, Cancer Research UK

Your research papers will be:

- available free of charge to the entire biomedical community

- peer reviewed and published immediately upon acceptance

- cited in PubMed and archived on PubMed Central

- yours - you keep the copyright

Submit your manuscript here:

http://www.biomedcentral.com/info/publishing_adv.asp
BioMedcentral 